\title{
A Promising Serum Autoantibody Marker, Anti-Heat Shock Protein 90 $\alpha$, for Cholangiocarcinoma
}

\author{
Sirintip Boonjaraspinyo ${ }^{1,2}$, Amornrat Juasook ${ }^{3}$, Thidarut Boonmars ${ }^{2,4 *}$, \\ Ratchadawan Aukkanimart ${ }^{2,4,5}$, Atit Silsirivanit ${ }^{2,6}$, Watcharin Loilome ${ }^{2,6}$, Pranee \\ Sriraj $^{2,5}$, Zhiliang $\mathrm{Wu}^{7}$, Panaratana Ratanasuwan ${ }^{8}$
}

\begin{abstract}
The present study was designed to investigate cholangiocarcinoma (CCA) antibodies in hamster serum. Hamster CCA cell lines were processed using sodium dodecyl sulfate-polyacrylamide gel electrophoresis and matrix-assisted laser desorption/ionization time-of-flight mass spectrometry. A candidate biomarker was confirmed by immunoprecipitation and western blot, and was further analyzed using ELISA and sera from normal control hamsters, hamsters with opisthorchiasis and hamsters with various stages of CCA, as well as from CCA patients and healthy individuals. One candidate marker was identified as HSP90 $\alpha$, as indicated by a high level of anti-HSP90 $\alpha$ in hamster CCA sera. It was found that the levels of anti-HSP90 $\alpha$ were specifically elevated in the sera of hamsters with CCA compared with other groups and progressively increased with the clinical stage. At the cut-off point of 0.4850 on the receiver operating characteristic curve, anti-HSP90 $\alpha$ could discriminate CCA from healthy control groups with a sensitivity of $76.2 \%$, specificity of $71.4 \%$ and total accuracy $75.5 \%$. In the present study, we have shown that anti-HSP90 $\alpha$ may be a potential useful serum biomarker to discriminate CCA cases from healthy persons.
\end{abstract}

Keywords: Serum autoantibody marker - anti-heat shock protein $90 \alpha$ - liver fluke - cholangiocarcinoma

Asian Pac J Cancer Prev, 16 (14), 5779-5785

\section{Introduction}

Cholangiocarcinoma (CCA) is a carcinoma arising from the epithelium of intrahepatic and extrahepatic bile ducts. The highest prevalence of CCA is in northern Thailand, an endemic area of the liver fluke, Opisthorchis viverrini $(\mathrm{OV})$, infestation (IARC, 2011; Sithithaworn et al., 2014), a serious medical problem in this region and one that is causally linked to the development of CCA (IARC, 2011). CCA is an incurable and rapidly lethal disease if the tumors cannot be removed completely. In non-resectable hilar CCA patients, the overall median and 1-, 3-, and 5-year survival rates were 13 months and 52, 12 and 7\%, respectively (Ruys et al., 2012). The median overall survival rate for resected patients is 18.9 months versus 5.0 months for patients not resected (Schiffman et al.,2011). Patients may receive palliative chemotherapy or radiation therapy, but these are not effective for treatment of late-stage disease (Friman, 2011). Unfortunately, CCA is asymptomatic in its early stages and first diagnosis is usually at an advanced stage (Khan et al., 2012). Therefore, the prognosis of CCA is poor and survival time is short (Schiffman et al., 2011; Khan et al., 2012; Ruys et al., 2012).

In order to find candidate biomarkers, hamster CCA cell lines were analyzed using one-dimensional SDSPAGE, followed by identification of protein using matrixassisted laser desorption/ ionization time-of-flight mass spectrometry (MALDI-TOF MS) and ELISA assay.

\section{Materials and Methods}

\section{Human ethics}

Human sera were provided from the Liver Fluke and Cholangiocarcinoma Center, Khon Kaen University and approved by the Ethics committee Khon Kaen University based on the principles of the Declaration of Helsinki and ICH-CCP (HE551236).

\section{Parasite preparation}

Fresh water fish were bought from the local market in Khon Kaen Province, northeast Thailand, an area endemic for opisthorchiasis. The fresh fish were digested using $0.25 \%$ pepsin- $1.5 \% \mathrm{HCl}$ solution, incubated at $37^{\circ} \mathrm{C}$ for

${ }^{1}$ Department of Community Medicine, ${ }^{4}$ Department of Parasitology, ${ }^{6}$ Department of Biochemistry, ${ }^{2}$ Neglected and Vector BorneZoonosis Research Group, Liver Fluke and Cholangiocarcinoma Research Center, ${ }^{8}$ Department of Anesthesiology, Faculty of Medicine, Khon Kaen University, Khon Kaen, ${ }^{3}$ Faculty of Veterinary Medicine, Mahasarakham University, Mahasarakham, ${ }^{5}$ Department of Traditional Medicine, Faculty of Natural Resources, Rajamangala University of Technology ISAN, Sakon Nakhon, Thailand, ${ }^{7}$ Department of Parasitology, Graduate School of Medicine, Gifu University, Gifu, Japan *For correspondence: bthida@ kku.ac.th; boonmars@yahoo.com 
$1 \mathrm{~h}$, filtered through 1000, 300, 250 and $106 \mu \mathrm{m}$ sieves and metacercariae were recovered via sedimentation in normal saline in a sedimentation jar. OV metacercariae, which have a double-walled cyst, oval shape, and oral and ventral suckers, could be clearly seen under a dissecting microscope. Each hamster was infected with 50 metacercariae by intragastric intubation.

\section{Animals}

Syrian hamsters, 6 weeks old, from the Animal Unit, Faculty of Medicine, Khon Kaen University, were divided into three groups ( 5 hamsters per group) as follows: group 1; uninfected (control); group 2; OV-infected (OV) and group 3; infected with OV and administered NDMA (OVN). Hamsters were sacrificed at 1, 2, 3 and 6 months post-infection. Whole blood ( $3 \mathrm{ml}$, by heart puncture) was collected separately from each hamster at the time of sacrifice and the sera kept at $-20^{\circ} \mathrm{C}$ for immune-western blotting assay. CCA masses collected from livers of group 3, hamsters were used to establish hamster CCA cell lines. All work was conducted with the approval of the Khon Kaen University Animal Ethics Committee (AEKKU51/2555).

\section{Administration of NDMA for induction of cholangiocarcinoma}

NDMA (final concentration $12.5 \mathrm{ppm}$ in drinking water) was administered every day from day 1 of the experiment for 2 months for inducing cholangiocarcinoma (Juasook et al., 2013).

\section{Establishment of hamster CCA cell lines}

Primary cholangiocarcinoma Syrian hamster cell lines were cultured in 10\% Dulbecco's Modified Eagle Medium (DMEM, Invitrogen) supplemented with $10 \%$ fetal bovine serum (FBS, Invitrogen), $100 \mathrm{U} / \mathrm{ml}$ penicillin, $100 \mathrm{mg} / \mathrm{ml}$ streptomycin and $0.25 \mathrm{mg} / \mathrm{ml}$ amphotericin B (antibioticantimycotic, Invitrogen). Cells were maintained in an incubator with humidified atmosphere of $95 \%$ air and $5 \% \mathrm{CO}_{2}$ at $37^{\circ} \mathrm{C}$. Cell culture techniques were performed using standard protocols (Boonjaraspinyo et al., 2012b).

\section{Hamster CCA cell line protein extraction}

Cells were allowed to grow until 80-90\% confluent and were subsequently harvested using trypsin digestion and then washed three times with phosphate buffered saline. Approximately $3 \times 10^{6}$ cells were then spun down in a 1.5 $\mathrm{ml}$ microcentrifuge tube $\left(4^{\circ} \mathrm{C}, 10\right.$ minutes, $\left.220 \mathrm{~g}\right), 500 \mu \mathrm{l}$ of PBS added to the pellets in the $1.5 \mathrm{ml}$ centrifuge tube and the cells disrupted on ice using an ultra-sonicator (Vibra Cell $^{\mathrm{TM}}$, Inc, USA). Following centrifugation, the supernatant was transferred to a new $1.5 \mathrm{ml}$ centrifuge tube and the protein concentration measured using a spectrophotometer at $280 \mathrm{~mm}$. Tubes were then kept at $-80^{\circ} \mathrm{C}$ until use.

Gel electrophoresis and immune-western blotting using hamster CCA lysate and OV sera

$15 \mu \mathrm{g}$ of whole cell lysate with an equal volume of 2x electrophoresis sample buffer was boiled for 2-3 min. Up to $10 \mu \mathrm{l}$ of lysate was loaded into each well of duplicate $12 \%$ polyacrylamide gels of $0.75 \mathrm{~mm}$ thickness (Amersham $^{\mathrm{TM}}$ ECL $^{\mathrm{TM}}$ Gel 12\% (GE Healthcare BioScience, Sweden). One gel was stained with Coomassie blue (AppliChem, Germany) and the other was used to transfer proteins to a nitrocellulose membrane (Bio-Rad Laboratories, USA) using an electro-blotting apparatus according to the manufacturer's protocols. The Coomassie blue-stained gel was dried and kept for gel digestion. The nitrocellulose membrane on which proteins from the other gel were blotted was blocked against non-specific binding using $0.5 \%$ skim milk at $4^{\circ} \mathrm{C}$ overnight in a covered box. The membrane was then washed three times for five min each with TBST (10mM Tris, $154 \mathrm{mM} \mathrm{NaCl}$, pH7.5 plus $0.1 \%$ Tween 20 ). The membrane was then incubated with each OV serum (dilution of $1: 100$ in $0.5 \%$ skim milk) at 1 , 2 and 3 month(s) and OVN serum at 1,2,3 and 6 months at $37^{\circ} \mathrm{C}$ for $1.5 \mathrm{~h}$ and then washed three times for five min each with TBST. The membrane was then incubated with a $2^{\text {nd }}$ antibody, hamster IgG peroxidase (Rabbit Envision (Dako North America, Inc.) at a dilution of 1:10000 in $0.5 \%$ skim milk at $37^{\circ} \mathrm{C}$ for $1.5 \mathrm{~h}$ and finally washed three times for five min each with TBS and developed using the ECL Gel Box (GE Healthcare Bio-Science, Sweden). Photos were taken using Molecular Imager ${ }^{\circledR}$ Gel Doc ${ }^{\mathrm{TM}}$ XR (Bio-Rad Laboratories, Inc.).

Gel electrophoresis and immune-western blotting for anti-HSP90a

Preparation of immunoprecipitation: In brief, hamster CCA antigen was solubilized in $50 \mu 1$ of immunoprecipitation buffer and a molar excess of hamster sera or HSP90 $\alpha$ added to the protein solution containing the antigen of interest. The volume of the sample was adjusted to $0.2 \mathrm{ml}$ with immunoprecipitation buffer and the sample incubated overnight at $4^{\circ} \mathrm{C}$. An appropriate amount of immobilized protein $\mathrm{A}$ or $\mathrm{G}$ was added to the antigenantibody complex and the sample incubated with gentle mixing for $2 \mathrm{~h}$ at room temperature. The immobilized protein A or G-bound complexes were washed with $0.5 \mathrm{ml}$ of the immunoprecipitation buffer, followed by centrifugation for 2-3 min in a microcentrifuge and the supernatant discarded. This washing procedure was repeated at least six times. The bound antigen-antibody complex from the immobilized protein $\mathrm{A}$ or $\mathrm{G}$ was eluted by incubation for five min with $50 \mu 1$ of the elution buffer. After centrifugation, the supernatant was collected and the gel incubated (five minutes) with another $50 \mu 1$ of the elution buffer and the process repeated. The two 50 $\mu 1$ supernatant samples were combined and immediately adjusted to a physiological $\mathrm{pH}$ by addition of a suitable, more concentrated buffer such as 1.0 M Tris, pH 7.5 (10 $\mu 1$ of this buffer to $100 \mu 1$ of the supernatant was usually sufficient). The eluted fraction was desalted. The sample was then ready for gel electrophoresis.

Gel electrophoresis and immunowestern blotting: Fifteen $\mu \mathrm{g}$ of whole cell lysate - bound with protein $\mathrm{G}$ (GE Healthcare Bio-Science, Sweden) was mixed with an equal volume of $2 x$ electrophoresis sample buffer and boiled for 2-3 min. Up to $10 \mu 1$ of lysate was loaded into each well of duplicate $12 \%$ acrylamide gels of $0.75 \mathrm{~mm}$ thickness (Amersham $^{\mathrm{TM}}$ ECL $^{\mathrm{TM}}$ Gel 12\% (GE healthcare Bio- 
Science, Sweden). One gel was developed with Coomassie blue (AppliChem, Germany) and from the other gel, proteins were transferred to a nitrocellulose membrane (Bio-Rad Laboratories) using an electro-blotting apparatus according to the manufacturer's protocols. The Coomassie blue stained gel was dried and kept for gel digestion. The nitrocellulose membrane on which proteins from the other gel were blotted was blocked against non-specific binding using $0.5 \%$ skim milk at $4^{\circ} \mathrm{C}$ overnight in a covered box. The membrane was washed three times for $5 \mathrm{~min}$ each with TBST. The membrane was then incubated with (anti-Hsp90 $\alpha$ antibody (Abcam ${ }^{\circledR}$ discover more, England) at $37^{\circ} \mathrm{C}$ for $1.5 \mathrm{~h}$ and then washed three times for $5 \mathrm{~min}$ each with TBST, incubated with a $2^{\text {nd }}$ antibody rabbit IgG peroxidase Rabbit Envision (Dako North America, Inc.) with dilution of $1: 10000$ in $0.5 \%$ skim milk at $37^{\circ} \mathrm{C}$ for $1.5 \mathrm{~h}$ and finally washed membrane three times for $5 \mathrm{~min}$ each with TBS and developed Gel electrophoresis ECL Gel Box (GE healthcare Bio-Science, Sweden) then taken the photos using Molecular Imager ${ }^{\circledR}$ Gel Doc ${ }^{\mathrm{TM}}$ XR (BioRad Laboratories, Inc.).

\section{Protein analysis}

In-Gel Digest Procedure: Gel-associated contaminants that perturb protein digestion in Coomassie blue-stained gels were removed by washing for $40 \mathrm{~min}$ with $50 \%$ acetonitrile, drying for $10 \mathrm{~min}$ at room temperature, and then rehydrated with a protease solution. The washing and drying steps resulted in a substantial reduction of the gel slice volume that, when next swollen in the protease solution, readily absorbed the enzyme, facilitating digestion. The Coomassie blue staining procedure was modified by reducing acetic acid and methanol concentrations in the staining solution and by eliminating acetic acid in the destaining solution. The peptides resulting from the in-gel digestion were recovered by passive elution, in excellent yields, for structural characterization. Digested proteins were processed using multidimensional liquid chomatography (LC) and tandem mass spectrometry (MS/MS) to separate and fragment peptides.

Enzyme link immunosorbent assay for HSP90 : The levels of anti- HSP90 $\alpha$ in patient sera and hamster sera were determined using the indirect ELISA method. Ninety-six well microtitre plates were coated overnight at $4^{\circ} \mathrm{C}$ with $1 \mu \mathrm{g} / \mathrm{ml}$ of HSP90 $\alpha$ full-length protein (Abcam, MA, USA) in carbonated buffer and blocked for $1 \mathrm{~h}$ at room temperature with $0.5 \%$ skimmed milk. Sera from healthy individuals and CCA patients (dilution 1:320) and from experimental hamsters (dilution 1:20) of all three groups were added and incubated for $2 \mathrm{~h}$ at room temperature. Horseradish peroxidase (KPL, Gaithersburg, USA) was applied at a dilution of 1:2,000 for $2 \mathrm{~h}$ at room temperature and the plates were incubated again for $2 \mathrm{~h}$ at room temperature. Finally, the reaction products were visualized using SureBlue TMB peroxidase substrate solution (KPL, Gaithersburg, USA) and stopped using 1N $\mathrm{HCl}$. The optical density (OD) was measured at $450 \mathrm{~nm}$. of each group using TRIZOL

Invitrogen, Carlsbad, CA, USA) according to the manufacturer's instructions. The isolated RNA was treated with DNase I (RNase-Free DNase, Fermentas Inc., Ontario, Canada) in the presence of ribonuclease inhibitor (Fermentas Inc., Ontario, Canada). The treated RNA was extracted with phenol/ chloroform, precipitated with ethanol, and dissolved in RNase-free water. Reverse transcription was performed using M-MLV Reverse transcriptase (Fermentas Inc., Ontario, Canada) according to the manufacturer's instructions. In brief, $3 \mu \mathrm{g}$ of total RNA from each sample was placed in a new tube and $1 \mu 1$ of oligo(dT) 18 primers added followed by DEPC-treated water to $12 \mu 1$. The sample was gently mixed, spun down, and incubated at $70^{\circ} \mathrm{C}$ for 5 minutes. On ice, the following were added: $5 \mathrm{x}$ reaction buffer $4 \mu \mathrm{l}$; ribonuclease inhibitor $1 \mu 1,10 \mathrm{mM}$ dNTP mix $2 \mu 1$. Each tube was mixed gently and incubated at $37^{\circ} \mathrm{C}$ for 5 minutes. After that, $1 \mu \mathrm{l}$ of M-MLV reverse transcriptase was added. The reaction was incubated at $42^{\circ} \mathrm{C}$ for $60 \mathrm{~min}$ and then inactivated by heating at $70^{\circ} \mathrm{C}$ for $10 \mathrm{~min}$ (Boonmars et al., 2011).

\section{Relative polymerase chain reaction}

Real time-RT-PCR, using the SYBR ${ }^{\circledR}$ Green method, was performed to quantify mRNA expression as previous describe (Boonjaraspinyo et al., 2012a). PCRs were set up in 96-well real-time PCR plates. The PCR reaction mixture comprised $2 \mu \mathrm{l}$ of 10x HotStart Taq buffer, $1 \mu \mathrm{l}$ of $5 \mathrm{mM}$ dNTP, $2.4 \mu \mathrm{l}$ of $25 \mathrm{mM} \mathrm{MgCl} 2,1 \mu \mathrm{l}$ of $5 \mu \mathrm{M}$ primer pairs, $0.2 \mu \mathrm{l}$ of HotStart Taq DNA polymerase (Fermentas Inc., Ontario, Canada) and $6.4 \mu 1$ of distilled water to give a final volume of $20 \mu 1$. Three $\mu 1$ of cDNA template was added to the reaction mixture and the plate briefly spun down. The analysis was performed using an Applied Biosystems 7500 Fast Real-Time PCR System. All values were normalized relative to a standard curve and reported as a copy number change over the background of housekeeping gene (G3PDH) level.

\section{Statistical analyses}

We used SPSS software version 17.0 (SPSS Inc., USA) to conduct all statistical comparisons. The difference between two independence groups were analyze by Student's t-test. One-way ANOVA was performed for compare means of three or more samples group. Twotailed $P$ values of 0.05 or less were considered significant. Receiver operating characteristic (ROC) analysis was used to detect the optimal cut-off points (i.e. those with the highest total accuracy) for separating CCA from other tested groups.

\section{Results}

$1 D$ gel electrophoresis and immuno-western blotting from hamster sera

Figure 1 shows the result of Coomassie blue-stained gels using hamster CCA lysate and membrane-transferred hamster CCA lysate incubated with hamster sera. A cross reaction was found at about $64-98 \mathrm{kDa}$ in all serum groups but the intensity of the band differed. Intensity was very low when normal hamster serum was used and increased 
Sirintip Boonjaraspinyo et al

with duration of the OV infection, 1,2 and 3 month (s) post infection. For the CCA hamster model (OV plus NDMA), the cross-reaction band was more intense, especially at 3 and 6 months.

Protein identification and gene expression in hamster CCA model

Coomassie blue-stained gels (Figure 2) were estimated bands with nitrocellulose membrane band and cut for protein analysis. Protein identification was differentially expressed in hamster CCA cells. Ions score is $-10 * \log$ $(\mathrm{P})$, where $\mathrm{P}$ is the probability that the observed match is a random event. Individual ions scores $>34$ indicate identity or extensive similarity $(\mathrm{p}<0.05)$. These differentially expressed protein bands were furthermore identified by in-gel trypsin digestion and the subsequent MALDI-TOF MS and Peptide mass matching identified two different protein products that were differentially expressed in hamsters with CCA. The identifications were based on protein sequence coverage $48 \%$ matched peptide matching peptides, numbers statistically necessary for a confident match (Figure 3 ) and Table 1. Of the two proteins (HSP90 $\alpha$ and elongation factor 2), only HSP90 $\alpha$ was confirmed (Figure 4) and further studied. HSP90 $\alpha$

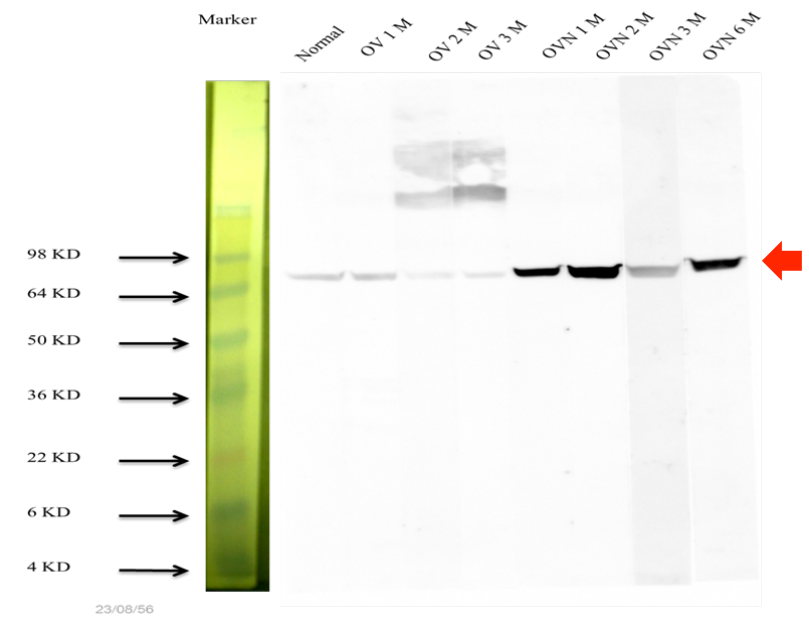

Figure 1. Immuno-western blotting of normal hamster (Normal), Opisthorchis viverrini infected for 1 month (OV1M), O. viverrini infected for 2 months (OV2M), O. viverrini infected for 3 months ( OV3M), $O$. viverrini infected and NDMA administered for 1 month (OVN1M), O. viverrini infected and NDMA administered for 2 months (OVN2M), O. viverrini infected and NDMA administered for 3 months ( OVN3M) and $O$. viverrini infected and NDMA administered for 6 months (OVN 6M) gene expression was observed in all groups (Figure 5), normal control, OV alone and OVN but the expression was different in intensity due to upregulation in OVN at three months of CCA development. Relative to uninfected controls, HSP90 $\alpha$ expression in OV infected hamsters was 2-5 fold greater and 2-14 fold greater in the OVN groups. The highest expression was observed at 2 months in both the OV and OVN groups and was statistically significantly higher in the OVN group $(\mathrm{P}<0.001)$. At 6 months, the HSP90 $\alpha$ expression was lower than at $2 \mathrm{M}$ in both groups but still higher than uninfected normal controls. In the OVN group, expression was significantly

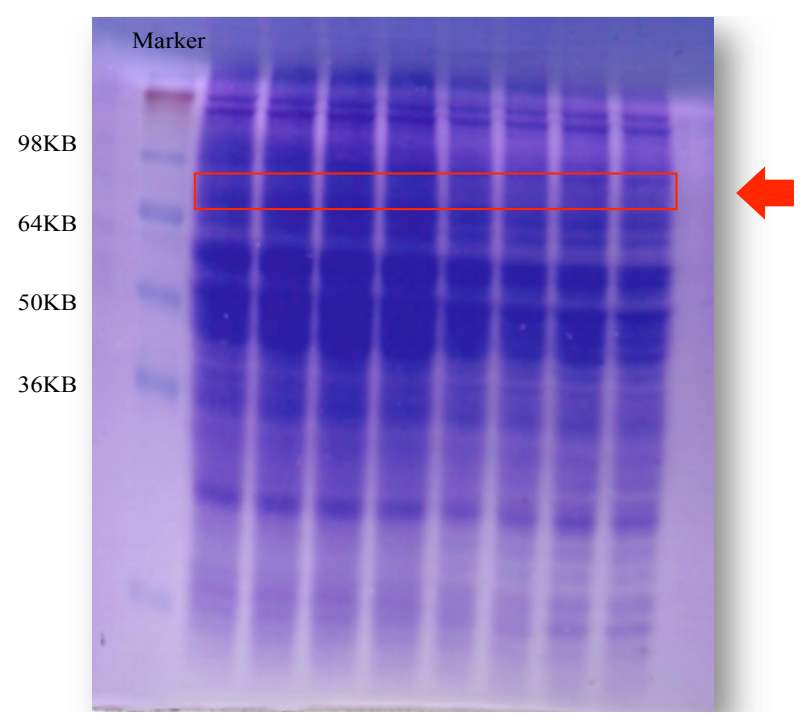

Figure 2. Gel Electrophoresis and Selected Band for Protein Identification (Arrow)

$\begin{array}{clll}1 \text { MPEETQTQDQ } & \text { PMEEEEVETF } & \text { AFQAEIAQLM } & \text { SLIINTFYSN } \\ 51 \text { NSSDALDKIR } & \text { YESLTDPSKL } & \text { DSGKELHINI } & \text { IPNKQDRTLT } \\ 101 \text { ADLINNLGTI } & \text { AKSGTKAFME } & \text { ALQAGADISM } & \text { IGQFGVGFYT } \\ 151 \text { ITKHNDDEQY } & \text { AWESSAGGSF } & \text { TVRTDTGEPM } & \text { GRGTKVILHL } \\ 201 \text { RRIKEIVKKH } & \text { SQFIGYPITL } & \text { FVEKERDKEV } & \text { SDDEAEEKED } \\ 251 \text { GIDDKPEIED } & \text { VGSDEEEEEK } & \text { KDGDKKKKKK } & \text { IKEKYIDQEE } \\ 301 \text { NPDDITNEEY } & \text { GEFYKSLTND } & \text { WEEHLAVKHF } & \text { SVEGQLEFRA } \\ 351 \text { DLFENRKKKN } & \text { NIKLYVRRVF } & \text { IMDNCEELFP } & \text { EYLNFIRGVV } \\ 401 \text { REILQQSKIL } & \text { KVIRKNLVRK } & \text { CLELFHELAE } & \text { DKENYKKFYE } \\ 451 \text { HEDSQNRKKL } & \text { SELLRYYTSA } & \text { SGDEMVSLKD } & \text { YCTRMKENQK } \\ 501 \text { DQVANSAFVE } & \text { RLRKHGLEVI } & \text { YMIEPIDEYC } & \text { VQQLKEFEGK } \\ 551 \text { ELPEDEEEKK } & \text { KQEEKKTKFE } & \text { NLCKIMKDIL } & \text { EKKVEKVVVS } \\ 601 \text { VTSTYGWTAN } & \text { MERIIKAQAL } & \text { RDNSTMGYMA } & \text { AKKHLEINPD } \\ 651 \text { AEADKNDKSV } & \text { KDLVILLYET } & \text { ALLSSGFSLE } & \text { DPQTHANRIY } \\ 701 \text { EDDPTVDDTS } & \text { AAVTEEMPPL } & \text { EGDDDTSRME } & \text { EVD }\end{array}$

Figure 3. Amino Acid Sequences of Peptides from Acrylamide Gels. There was $48 \%$ coverage shown in bold red is HSP90 $\alpha$

Table 1. Proteins identified as Differentially Expressed in the Hamster CCA Cell Line

\begin{tabular}{llllccc}
\hline Accession No. & \multicolumn{1}{c}{ Protein name } & PI & Mr & MOWSE score & Matches & Sequence coverage (\%) \\
\hline HS90B_MOUSE & Heat shock protein HSP 90-beta & 9.4 & 83571 & 1412 & 73 & 49 \\
HS90A_RAT & Heat shock protein HSP 90-alpha & 5.51 & 85161 & 1111 & 62 & 45 \\
HS90A_CRIGR & Heat shock protein HSP 90-alpha & 4.48 & 85195 & 1022 & 57 & 41 \\
EF2_MOUSE & Elongation factor 2 & 1.67 & 96222 & 649 & 29 & 24 \\
EF2_CRIGR & Elongation factor 2 & 1.67 & 96205 & 629 & 29 & 24 \\
\hline
\end{tabular}

*PI=the isoelectric point; $\mathrm{Mr}=$ average mass of the protein ; MOWSE score=Molecular Weight Search is a protein identification method using molecular weight of peptides 
higher $(\mathrm{P}<0.001)$ than in the $\mathrm{OV}$ group.

Anti-HSP90 antibody levels in human and hamster sera assayed using ELISA

Evaluation of antibody to HSP90 $\alpha$ was performed using ELISA in human and hamster sera using the ROC curve analysis of serum antibody to HSP90 $\alpha$ for discriminating CCA patients from healthy individuals (Figure 6). The area under the curve (AUC) was 0.7925 (95\% confidence interval, 0.6198 to 0.9652 ), and the cut off value of the serum HSP90 $\alpha$ optical density (OD) level was $0.4850 \mathrm{U} \mathrm{ml}^{-1}$ (sensitivity, $76.19 \%$; specificity, $71.43 \%$; LR+, 2.67).

In the hamster model, the HSP90 $\alpha$ levels were determined at 1,2,3 and 6 month(s) p.i. in the three groups (Figure 7). The range of antibody to HSP90 $\alpha$ in normal hamster sera at these time points was $0.115-0.155 \mathrm{U} \mathrm{ml}^{-}$ ${ }^{1}$. The levels of anti-HSP90 $\alpha$ in the group OV and OVN were higher than in normal hamster controls at 3 and 6 months. The mean serum level of anti-HSP90 $\alpha$ increased from 0.115 in normal controls to 0.191 at 3 months and the highest was 0.206 at 6 months p.i. in the group infected with $O$. viverrini and given NDMA.

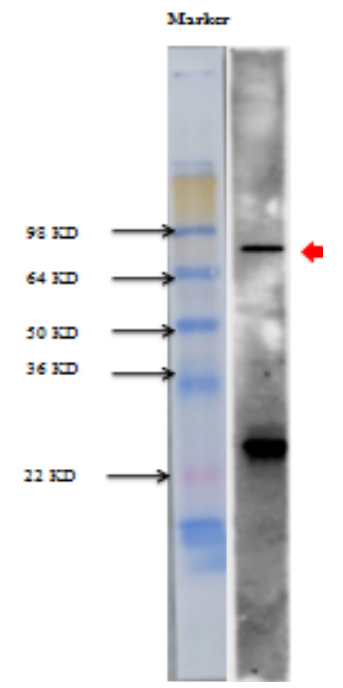

Figure 4. Gel Electrophoresis and Western Blotting Analysis to Confirming the Anti-HSP90 $\alpha$ in Serum

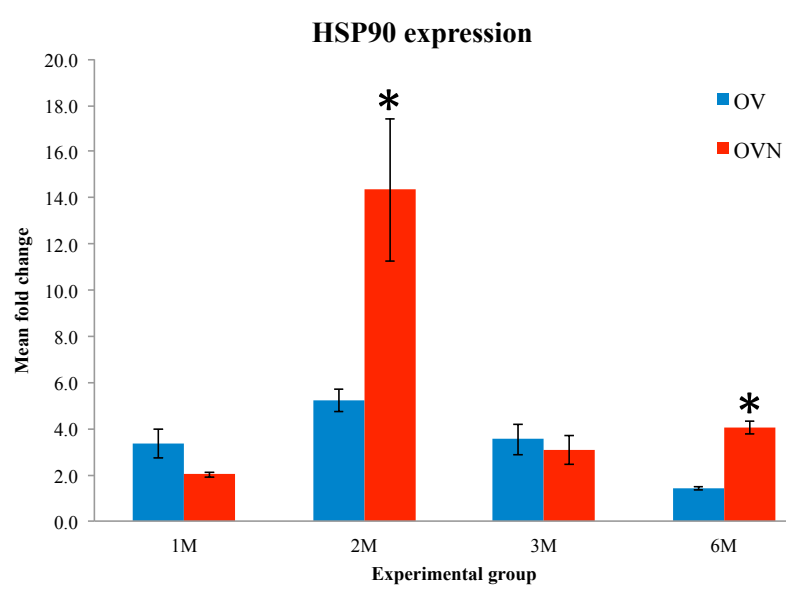

Figure 5. HSP $90 \propto$ Gene Expression. *statistically significant difference $(\mathrm{P}<0.05)$
The mean serum anti-HSP90 $\alpha$ level obtained from seven healthy human controls was $0.450 \pm 0.054$ and the range from 0.259 to $0.683 \mathrm{U} \mathrm{ml}^{-1}$ (Figure 8). Sera from 42

ROC curve of antibody to HSP90

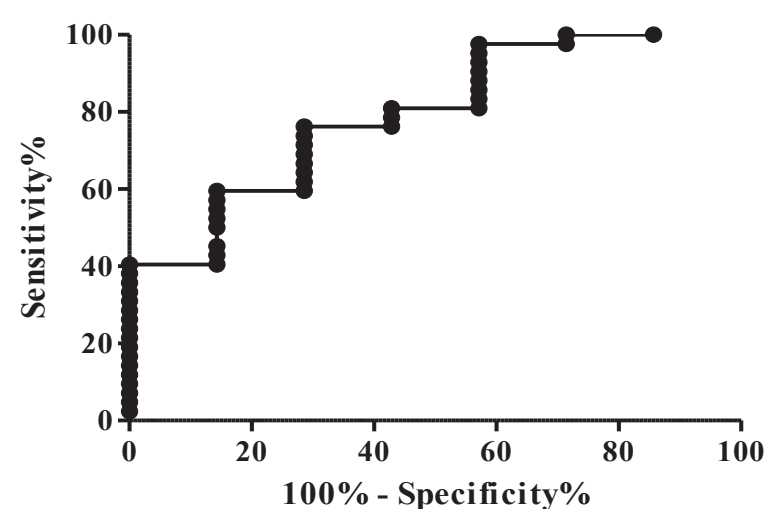

Figure 6. ROC Curve Analysis of Serum Antibody to HSP90 $\alpha$ for Discriminating CCA Patients from Healthy Individuals

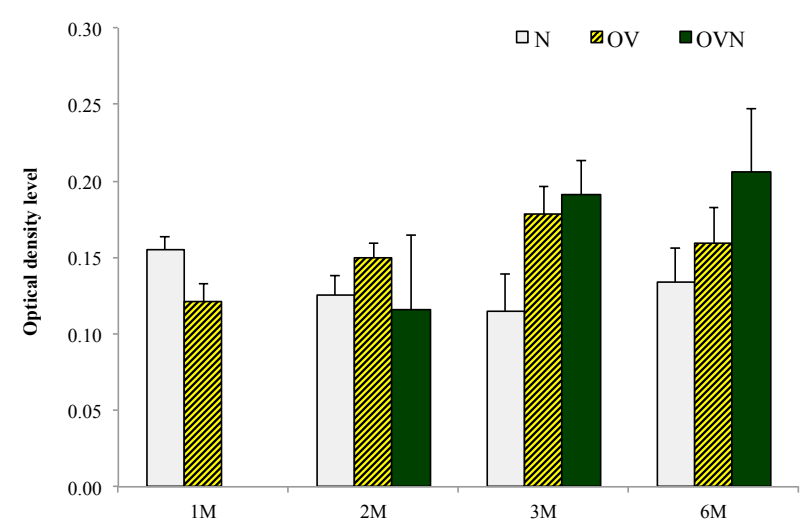

Figure 7. Levels of Serum Antibody to HSP90 $\alpha$ in the three Groups of Hamsters (normal control, $O$. viverrini Infection and Infection Plus NDMA;OVN) at Various Stages (1, 2, 3 and 6 Month (s) p.i.). The anti-HSP90 $\alpha$ serum level was presented as the mean \pm SEM from five hamsters in each group. OVN was trend to higher than normal

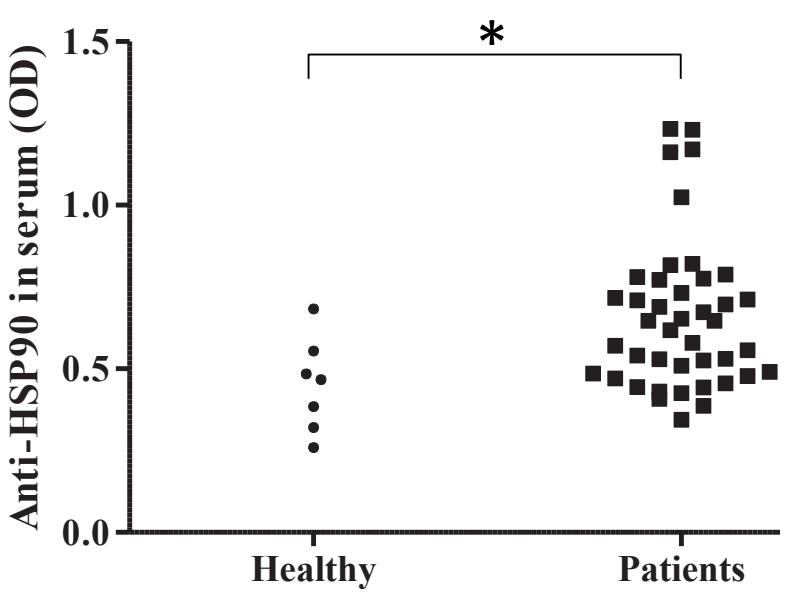

Figure 8. Levels of Serum Antibody to HSP90a in CCA Patients Compared with Healthy Controls. *P-value < 0.05 , determined using Student's t-test. 


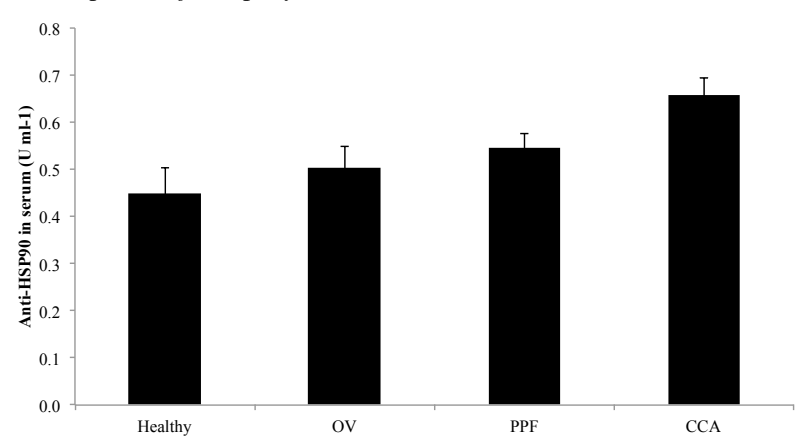

Figure 9. Levels of Serum Antibody to HSP90 in Healthy Controls Compared with $\boldsymbol{O}$. Viverrini Infection (OV), Periportal Fibrosis (PPF) and CCA Patients. The HSP90 serum level was presented as the mean \pm SEM

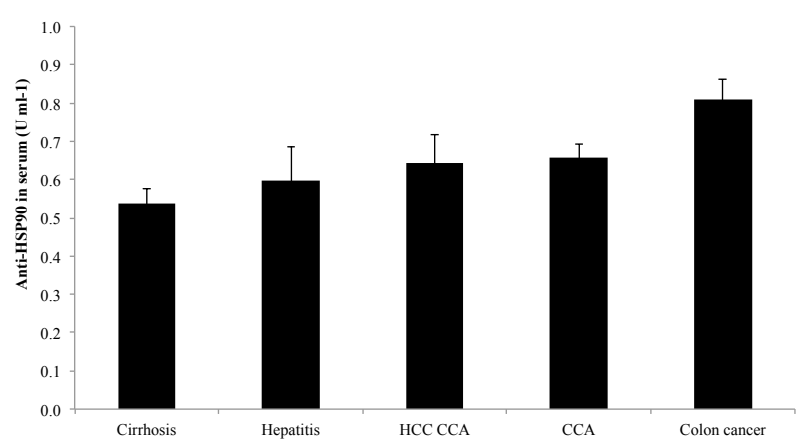

Figure 10. Levels of Serum Antibody to HSP90a in CCA Patients Compared with other Diseases, Hepatocellularcarcinoma-cholangiocarcinoma (HCC CCA) and Colon Cancer. The anti-HSP90 $\alpha$ serum level is shown as the mean \pm SEM

CCA patients had a mean of $0.659 \pm 0.035$ and ranged from 0.344 to 1.233 . The anti-HSP90 $\alpha$ levels in CCA patient sera were significantly higher than in healthy control sera by 1.5 fold $(\mathrm{p}=0.024$, $t$-test $)$.

The comparisons of serum levels of anti-HSP90 $\alpha$ in people with $O$. viverrini infection, periportal fibrosis, CCA patients and healthy volunteers are shown in Figure 9. The serum levels of anti-HSP90 $\alpha$ in $O$. viverrini infections patients were $0.504 \pm 0.043 \mathrm{U} \mathrm{ml}^{-1}$ and ranged from 0.277 to $0.726 \mathrm{U} \mathrm{ml}^{-1}$. Sera from periportal fibrosis patients were $0.545 \pm 0.031 \mathrm{U} \mathrm{ml}^{-1}$ and ranged from 0.307 to 0.783 $\mathrm{U} \mathrm{ml}^{-1}$. The serum anti-HSP90 $\alpha$ levels in people with $O$. viverrini infection, periportal fibrosis and CCA patients were higher than in healthy control serum $(1.1,1.2$, and 1.5 fold, respectively-Figure 9). Anti-HSP90 $\alpha$ levels in CCA patients $(0.659 \pm 0.035)$ were higher than in patients with cirrhosis $(0.538 \pm 0.039)$, hepatitis $(0.598 \pm 0.089)$, and HCC CCA $(0.642 \pm 0.076)$ but lower than in patients with colon cancer $(0.811 \pm 0.052)$. However, there was no significant difference between patients with CCA and these diseases (Figure 10).

\section{Discussion}

The present study is the first report to show that the serum marker, anti-HSP90 $\alpha$, increased significantly in a time-dependent manner during CCA development, suggesting that anti-HSP90 $\alpha$ is a promising diagnostic and or prognostic biomarker for CCA in the hamster model. HSPs are induced during heat shock and by other stimuli, such as infections, inflammation, oxidative stress and growth factors (Kim and Yenari, 2013; Tomcik et al., 2014). These proteins correct the conformation of misfolded proteins and helps incorrigibly misfolded proteins to be removed (Hong et al., 2013). HSPs provide either the stability or the proteasomal degradation of selected proteins under stress conditions thus contributing to cell survival (Jego et al., 2013). HSPs have been classified according to their molecular weight (Jego et al., 2013). HSP90 is an important chaperone that interacts with and refolds its client proteins in a cycle that is driven by the binding and hydrolysis of ATP (Patel et al., 2011). In normal condition, HSPs have been shown to act as intercellular signaling molecules, which merits their inclusion among hormones, cytokines, and growth factors (Khalil et al., 2011). Normal cells, HSP90 is response to tissue injury from the environmental insults, including heat, hypoxia, UV, gamma-irradiation, reactive oxygen species (ROS), injury-released growth factors but tumor cells also recognize the usefulness of HSP90 in tissue invasion and metastasis (Li et al., 2012). HSP90 is implicated in maintaining the conformation, stability, activity and cellular localization of several key oncogenic client proteins that are involved in signal transduction pathways leading to the proliferation, cellcycle progression, apoptosis and angiogenesis (Messaoudi et al., 2011). HSP90 is over-expressed in cancer cells and several of its client proteins are signaling oncoproteins that represent nodal points in multiple oncogenic signaling pathways (Hong et al., 2013). The anti-apoptotic action of HSP90 is also reflected by its capacity to interact with Akt/PKB, TNF-receptor signaling and NF-kB (Khalil et al., 2011). As mention above, HSP90 $\alpha$ was observed in the normal cells and several tumors but there is no report of anti-HSP90 $\alpha$ in the sera of any cancers, even in animal models. Interestingly, this is the first report to show antiHSP90 $\alpha$ profiles in hamster CCA and in sera of CCA patients together with HSP90 $\alpha$ gene expression profiles in hamster CCA tissues and tissues from CCA patients (Boonjaraspinyo et al., 2012a).

The western blot of CCA hamster model showed a gradual increase in levels of anti-HSP90 $\alpha$ in OVN at 3 and 6 months, similar to the ELISA results that showed antibody to HSP90 $\alpha$ in hamster sera was elevated at 3 and 6 months in the OVN group. For CCA patients, a previous study showed that gene expression of HSP90 $\alpha$ was up-regulated in $76 \%$ of patients (Boonjaraspinyo et al., 2012a), consistent with findings of the present study, in which the anti-HSP90 $\alpha$ levels in patient sera significantly increased 1.5 fold compared to healthy volunteers ( $\mathrm{p}=0.024$, $t$-test $)$. This evidence seems to suggest that if tissue has a high level of HSP90 $\alpha$, there should be a high level of anti-HSP90 $\alpha$ in serum as well.

The ELISA analysis of sera from patients with various other liver diseases showed that anti-Hsp90 $\alpha$ levels were slightly increased in O. viverini infection and periportal fibrosis patients (1.1 and 1.2 fold, respectively) but not significantly so when compared with healthy volunteers. At the cut-off point of 0.4850 on the receiver operating characteristic curve, anti-HSP90 $\alpha$ could discriminate CCA 
from healthy control groups with a sensitivity of $76.19 \%$, specificity of $71.43 \%$ and total accuracy $75.51 \%$. The serum antibody levels to HSP90 $\alpha$ in CCA patients was higher than in cirrhosis, hepatitis, and HCC CCA, but lower than in colon cancer, and the difference was not significant. This finding was supported by the elevated HSP90 $\alpha$ expression levels in colon carcinomas with one third of tumors (Drecoll et al., 2014).

In conclusion, anti-HSP90 $\alpha$ is potentially a serological biomarker for hamster CCA. This autoantibody is present at concentrations related to the stage of CCA development. The serum level of anti-HSP90 $\alpha$, in combination with other markers, may be valuable for early detection of CCA and for prediction of the stage of the disease.

\section{Acknowledgements}

This study was supported by grants of Khon Kaen University (KKU56-57), the Higher Education Research Promotion and National Research University Project of Thailand, Office of the Higher Education Commission, though the Health Cluster (SHep-GMS) and Thailand research fund (RTA5580004).

\section{References}

Boonjaraspinyo S, Boonmars T, Kaewkes S, et al (2012a). Down-regulated expression of HSP70 in correlation with clinicopathology of cholangiocarcinoma. Pathol Oncol Res, 18, 227-37.

Boonjaraspinyo S, Boonmars T, Wu Z, et al (2012b). Plateletderived growth factor may be a potential diagnostic and prognostic marker for cholangiocarcinoma. Tumour Biol, 33, 1785-802.

Boonmars T, Wu Z, Boonjaruspinyo S, et al (2011). Involvement of c-Ski oncoprotein in carcinogenesis of cholangiocacinoma induced by Opisthorchis viverrini and N-nitrosodimethylamine. Pathol Oncol Res, 17, 219-27.

Drecoll E, Nitsche U, Bauer K, et al (2014). Expression analysis of heat shock protein 90 (HSP90) and Her2 in colon carcinoma. Int J Colorectal Dis, 29, 663-71.

Friman S (2011). Cholangiocarcinoma-current treatment options. Scand J Surg, 100, 30-4.

Hong DS, Banerji U, Tavana B, et al (2013). Targeting the molecular chaperone heat shock protein 90 (HSP90): lessons learned and future directions. Cancer Treat Rev, 39, 375-87.

IARC (2011). Opisthorchis viverrini and Clonorchis sinensis IARC. Monogr Eval Carcinog Risks Hum, 100, 347-76.

Jego G, Hazoume A, Seigneuric R, et al (2013). Targeting heat shock proteins in cancer. Cancer Lett, 332, 275-85.

Juasook A, Aukkanimart R, Boonmars T, et al (2013). Tumorrelated gene changes in immunosuppressive Syrian hamster cholangiocarcinoma. Pathol Oncol Res, 19, 785-94.

Khalil AA, Kabapy NF, Deraz SF, et al (2011). Heat shock proteins in oncology: diagnostic biomarkers or therapeutic targets? Biochim Biophys Acta, 1816, 89-104.

Khan SA, Davidson BR, Goldin RD, et al (2012). Guidelines for the diagnosis and treatment of cholangiocarcinoma: an update. Gut, 61, 1657-69.

Kim JY, Yenari MA (2013). The immune modulating properties of the heat shock proteins after brain injury. Anat Cell Biol, 46, 1-7.

Li W, Sahu D, Tsen F (2012). Secreted heat shock protein-90 (Hsp90) in wound healing and cancer. Biochim Biophys Acta, 1823, 730-41.

Messaoudi S, Peyrat JF, Brion JD, et al (2011). Heat-shock protein 90 inhibitors as antitumor agents: a survey of the literature from 2005 to 2010. Expert Opin Ther Pat, 21, 1501-42.

Patel HJ, Modi S, Chiosis G, et al (2011). Advances in the discovery and development of heat-shock protein 90 inhibitors for cancer treatment. Expert Opin Drug Discov, 6, 559-87.

Ruys AT, van Haelst S, Busch OR, et al (2012). Long-term survival in hilar cholangiocarcinoma also possible in unresectable patients. World J Surg, 36, 2179-86.

Schiffman SC, Reuter NP, McMasters KM, et al (2011). Overall survival peri-hilar cholangiocarcinoma: $\mathrm{R} 1$ resection with curative intent compared to primary endoscopic therapy. $J$ Surg Oncol, [Epub ahead of print].

Sithithaworn P, Yongvanit P, Duenngai K, et al (2014). Roles of liver fluke infection as risk factor for cholangiocarcinoma. $J$ Hepatobiliary Pancreat Sci, 21, 301-8.

Tomcik M, Zerr P, Pitkowski J, et al (2014). Heat shock protein 90 (Hsp90) inhibition targets canonical TGF-beta signalling to prevent fibrosis. Ann Rheum Dis, 73, 1215-22. 